\title{
Comparative study of GPS-TEC smoothing techniques
}

\author{
Mohamed Abdelazeem ${ }^{1,2} \cdot$ Rahmi N. Çelik ${ }^{1} \cdot$ Ahmed El-Rabbany $^{2}$
}

Received: 29 May 2015/Accepted: 20 November 2015/Published online: 9 December 2015

(C) Akadémiai Kiadó 2015

\begin{abstract}
The availability of permanent global positioning system (GPS) stations makes the ionosphere monitoring and space weather studies more attainable. In order to obtain precise ionosphere total electron content (TEC) measurements, a smoothing technique has to be used. The objective of this research is to examine the accuracy and performance of two different TEC smoothing techniques; the carrier phase smoothed code and code levelled carrier phase techniques. GPS data from three stations in North America, located in different latitudes, are used. The accuracy of the smoothed TEC is compared with international GNSS service global ionospheric maps (IGS-GIM) and national oceanic and atmospheric administration (NOAA) ionospheric maps. The results reveal that the accuracy of the estimated TEC from the phase-smoothed code method depends upon the quality of data, number of observations used in the smoothing interval, receiver and satellite differential code biases (DCB). The levelled carrier phase method produces more calibrated TEC, however, with the influence of the systematic errors and the differential code biases.
\end{abstract}

Keywords Ionosphere $\cdot$ GPS $\cdot$ TEC $\cdot$ Smoothing techniques

\section{Introduction}

GPS has become a powerful tool for real-time TEC estimation and space weather monitoring studies, where it provides 3D TEC representation in longitude, latitude and time. Currently, a number of regional and global GPS reference networks have been developed by different organizations such as the IGS-GIM. Each daily GIM file contains vertical TEC (VTEC) with a spatial resolution of $2.5^{\circ} \times 5^{\circ}$ in latitude and longitude, respectively, and a

Mohamed Abdelazeem

moh.azm84@gmail.com

1 Geomatics Engineering Department, Istanbul Technical University, Istanbul, Turkey

2 Civil Engineering Department, Ryerson University, Toronto, ON, Canada 
temporal resolution of $2 \mathrm{~h}$. The expected accuracy of the IGS-GIM is $2-8$ TEC units. More details on how these products are being generated, their performance and proposed improvement can be found in Hernández-Pajareset et al. (2009).

An example of a regional ionospheric product is the national oceanic and atmospheric administration United States total electron content maps (US-TEC), which are produced through the collaboration of different organizations. The model is designed to estimate TEC over the continental US (CONUS) in near real time. In addition, NOAA uses a Kalman filter data assimilation technique using data from a regional network consists of CORS, GPS/Met and IGS reference stations. Each US-TEC file contains the VTEC and slant TEC between points and GPS satellites in view. Its spatial and temporal resolution is $1^{\circ} \times 1^{\circ}$ and $15 \mathrm{~min}$, respectively. The expected accuracy of the US-TEC is about 1-3 TEC units (Araujo-Pradere et al. 2007).

In order to estimate precise TEC values, a smoothing technique has to be used in order to reduce the noise level of code observations and eliminating ambiguities in carrier phase observations. Since the smoothing technique is crucial issue and it might be one of the reasons to introduce negative TEC values while producing regional ionospheric model by using scientific GPS data processing software such as the Bernese software. The objective of this study is to investigate the accuracy and performance of two different smoothing techniques; the code levelled carrier phase and the carrier phase smoothed code. The TEC values are estimated and compared with the IGS-GIM and the NOAA US-TEC counterparts.

\section{Ionospheric observables}

The basic GPS observation equations can be expressed as follows (Kleusberg and Teunissen 1998):

$$
\begin{gathered}
P_{i}=\rho_{r}^{s}+c\left(d t_{r}-d t^{s}\right)+I_{r, i}^{s}+T_{r}^{s}+c\left(d_{r, i}+d_{i}^{s}\right)+\varepsilon_{p, i} \\
L_{i}=\rho_{r}^{s}+c\left(d t_{r}-d t^{s}\right)-I_{r, i}^{s}+T_{r}^{s}+c\left(\delta_{r, i}+\delta_{i}^{s}\right)+\lambda_{i} N_{i}+\varepsilon_{\varphi, i}
\end{gathered}
$$

where $P_{i}$ and $L_{i}$ are the pseudorange and carrier phase measurements in meter, respectively; $\rho_{r}^{s}$ is the satellite-receiver true geometric range; $c$ is the speed of light in vacuum; $d t_{r}$ and $d t^{s}$ are the receiver and satellite clock errors, respectively; $I_{r, i}^{s}$ the ionospheric delay; $T_{r}^{s}$ the tropospheric delay; $d_{r, i}$ and $d_{i}^{s}$ are the code hardware delay for the receiver and the satellite, respectively; $\delta_{r, i}$ and $\delta_{i}^{s}$ are the carrier phase hardware delay for the receiver and the satellite, respectively; $\lambda_{i}$ is the wavelength of carrier phase; $N_{i}$ is the noninteger phase ambiguity parameter, including the integer ambiguity and initial fractional phase biases in the receiver and the satellite channels; $\varepsilon_{p, i}$ and $\varepsilon_{\varphi, i}$ are the code and phase unmodeled errors, including noise and multipath.

Geometry-free linear combinations are formed using the zero-difference code and carrier phase observations, which eliminate the geometrical term, tropospheric delay, receiver and satellite clock errors as follows (Dach et al. 2007):

$$
P_{4}=P_{1}-P_{2}=\left(1-\frac{f_{1}^{2}}{f_{2}^{2}}\right) I_{r}^{s}+c\left(\Delta b_{r}+\Delta b^{s}\right)
$$




$$
L_{4}=L_{1}-L_{2}=\left(\frac{f_{1}^{2}}{f_{2}^{2}}-1\right) I_{r}^{s}+c\left(\Delta \delta_{r}+\Delta \delta^{s}\right)+\left(\lambda_{1} N_{1}-\lambda_{2} N_{2}\right)
$$

where $P_{4}$ and $L_{4}$ are the geometry-free combinations for the code and the phase observations, respectively in meters; $I_{r}^{s}$ is $L_{1}$ ionospheric delay; $\Delta b^{s}$ and $\Delta b_{r}$ are the differential code bias for the receiver and the satellite, respectively; $\Delta \delta_{r}$ and $\Delta \delta^{s}$ are the differential phase hardware delay for the receiver and the satellite, respectively.

\section{TEC smoothing techniques}

In order to improve the precision of the derived TEC, different smoothing techniques have been used. The smoothing process is achieved either on the raw data level then estimating TEC or on the derived TEC level (Liu et al. 2005). The two examined smoothing techniques, which are applied on the raw data level, are discussed as follows:

\subsection{Carrier phase smoothed code technique}

This method is firstly proposed by Springer (2000) and applied in Bernese software (Dach et al. 2007). It depends on smoothing the code observations using the carrier phase observations in a continuous data arc. The code observations are replaced by the phase observations shifted by the mean difference code-phase in the arc. The carrier phase smoothed code can be expressed as follows (Springer 2000):

$$
\begin{aligned}
& \bar{P}_{1}=L_{1}+\left(\bar{P}_{1}-\bar{L}_{1}\right)+2 \times \frac{f_{2}^{2}}{f_{1}^{2}-f_{2}^{2}} \times\left(\left(L_{1}-L_{2}\right)-\left(\bar{L}_{1}-\bar{L}_{2}\right)\right) \\
& \bar{P}_{2}=L_{2}+\left(\bar{P}_{2}-\bar{L}_{2}\right)+2 \times \frac{f_{1}^{2}}{f_{1}^{2}-f_{2}^{2}} \times\left(\left(L_{1}-L_{2}\right)-\left(\bar{L}_{1}-\bar{L}_{2}\right)\right)
\end{aligned}
$$

where $\bar{P}_{F}$ are smoothed code measurements; $\bar{P}_{F}-\bar{L}_{F}$ is mean difference between all the accepted code and phase measurements in the current observation arc; $L_{1}-L_{2}$ is the ionospheric delay; $\bar{L}_{1}-\bar{L}_{2}$ is the mean ionospheric delay in the observation arc.

\subsection{Code levelled carrier phase technique}

This technique is a levelling process of phase measurements using pseudorange observations for each connected observations arc in order to remove the ambiguity. The method is discussed in previous studies (e.g. Mannucci et al. 1998; Otsuka et al. 2000; Arikan et al. 2008). The geometry-free linear combination is formed for carrier phase and code observations and then the average of the differences between them is computed for every continuous arc. The levelled carrier phase ionospheric observable can be expressed as follows (Ciraolo et al. 2007):

$$
\bar{L}_{4}=L_{4}-\left(L_{4}-P_{4}\right)
$$

where

$$
\left(L_{4}-P_{4}\right)-\frac{1}{n} \sum_{1}^{n}\left(L_{4}-P_{4}\right)
$$


where $\bar{L}_{4}$ is the levelled carrier phase ionospheric observable; $n$ is the number of continuous measurements in the arc.

Based on Eqs. 3 and 4, the mathematical expression for Eq. 8 can be rewritten as follows:

$$
\left(L_{4}-P_{4}\right)=c\left(\Delta \delta_{r}-\Delta b_{r}\right)+c\left(\Delta \delta^{s}-\Delta b^{s}\right)+\left(\lambda_{1} N_{1}-\lambda_{2} N_{2}\right)
$$

Therefore, the levelled carrier phase ionospheric observable can be defined as follow:

$$
\bar{L}_{4}=\left(\frac{f_{1}^{2}}{f_{2}^{2}}-1\right) I_{r}^{s}+c\left(\Delta b_{r}+\Delta b^{s}\right)
$$

From Eq. 10, it can be seen that the carrier phase levelled technique is affected by the differential code bias. The slant total electron content can be estimated from each visible satellite using the carrier-smoothed observations and the code-levelled carrier phase observations, respectively as follows:

$$
\begin{gathered}
S T E C=\left(\frac{f_{1}^{2} f_{2}^{2}}{40.3\left(f_{1}^{2}-f_{2}^{2}\right)}\right)\left[\left(\bar{P}_{2}-\bar{P}_{1}\right)+\mathrm{c}\left(\Delta b_{r}+\Delta b^{s}\right)\right] \\
S T E C=\left(\frac{f_{1}^{2} f_{2}^{2}}{40.3\left(f_{1}^{2}-f_{2}^{2}\right)}\right)\left[\bar{L}_{4}+\mathrm{c}\left(\Delta b_{r}+\Delta b^{s}\right)\right]
\end{gathered}
$$

The vertical TEC is estimated using the single layer model (SLM) mapping function which assumes that all free electrons are concentrated in a shell of infinitesimal thickness at height $\mathrm{H}$ (Fig. 1). The effective height $(\mathrm{H})$ corresponds to maximum electron density at the F2 peak ranges from 350 to $450 \mathrm{~km}$. The VTEC is determined at the ionosphere pierce point (IPP), the point of intersection between the shell layer and satellite-receiver path, as given below (Schaer 1999):

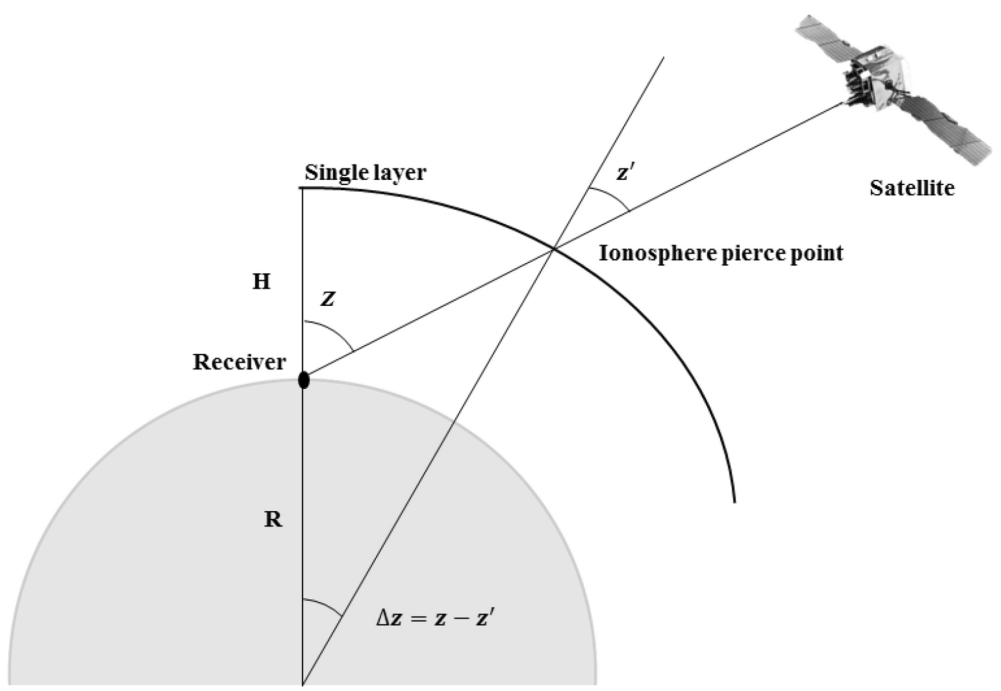

Fig. 1 Single layer model (SLM) 


$$
V T E C=S T E C \times \cos \left(\arcsin \left(\frac{R}{R+H} \sin (\alpha z)\right)\right)
$$

where $z$ is the satellite's zenith distance at receiver; $R$ is the mean radius of the Earth, and $H$ is the height of ionosphere thin shell layer.

In order to extract the vertical total electron content values from the IGS-GIM and the NOAA maps, the bivariate spatial interpolation technique using the nearest four TEC values (Fig. 2) is applied as follows (Schaer et al. 1998):

$$
T E C=(1-p)(1-q) T E C_{0,0}+p(1-q) T E C_{1,0}+q(1-p) T E C_{0,1}+p q T E C_{1,1}
$$

The temporal interpolation is also used in order to compute the total electron content value at time interval $(t)$, which takes the form (Schaer et al. 1998):

$$
T E C_{t}=\frac{T_{i+1}-t}{T_{i+1}-T_{i}} T E C_{i}+\frac{t-T_{i}}{T_{i+1}-T_{i}} T E C_{i+1}
$$

\section{Methodology}

Three IGS reference stations in North America are used in order to evaluate the two smoothing methods. The stations are distributed in different latitudes (Fig. 3) in order to reflect different ionospheric characteristics. Table 1 outlines the latitude, longitude and the receiver type of each station. GPS observations for three successive days (DOY 360, 361 and 362 in 2013) have been downloaded (IGS 2015). Table 2 shows the radio flux at $10.7 \mathrm{~cm}$ wavelength $\left(F_{10.7}\right)$ index and geomagnetic planetary $\left(A_{P}\right)$ index in the 3 days which represent the solar and geomagnetic activity, respectively. It can be shown that the solar activity is medium and the geomagnetic activity is quiet in the 3 days under consideration.

Each observation file has a 24-h time span and a 30-s time interval. The observation files have been processed using the zero-difference mode. The final IGS precise orbit products have been used to account for the satellite orbit errors (IGS 2015). For the phase-smoothed code method, the code observations have been smoothed using Eqs. 5 and 6 . The satellite elevation angles have been computed every $15 \mathrm{~min}$. The slant total electron content values have been estimated every 15 min time interval (Eq. 11). In addition, the differential code biases for both the satellites and the receivers have been extracted from the final IGS-GIM

Fig. 2 Bivariate interpolation technique

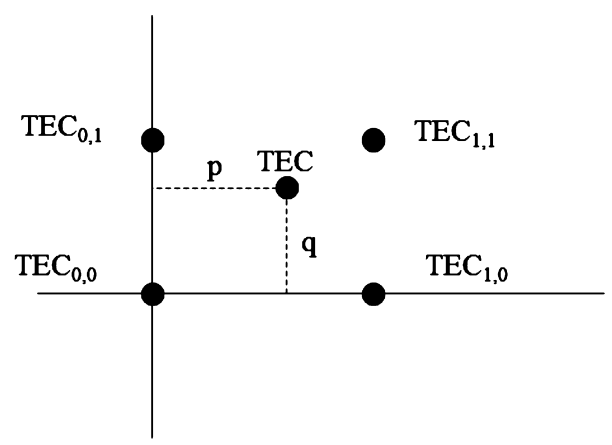




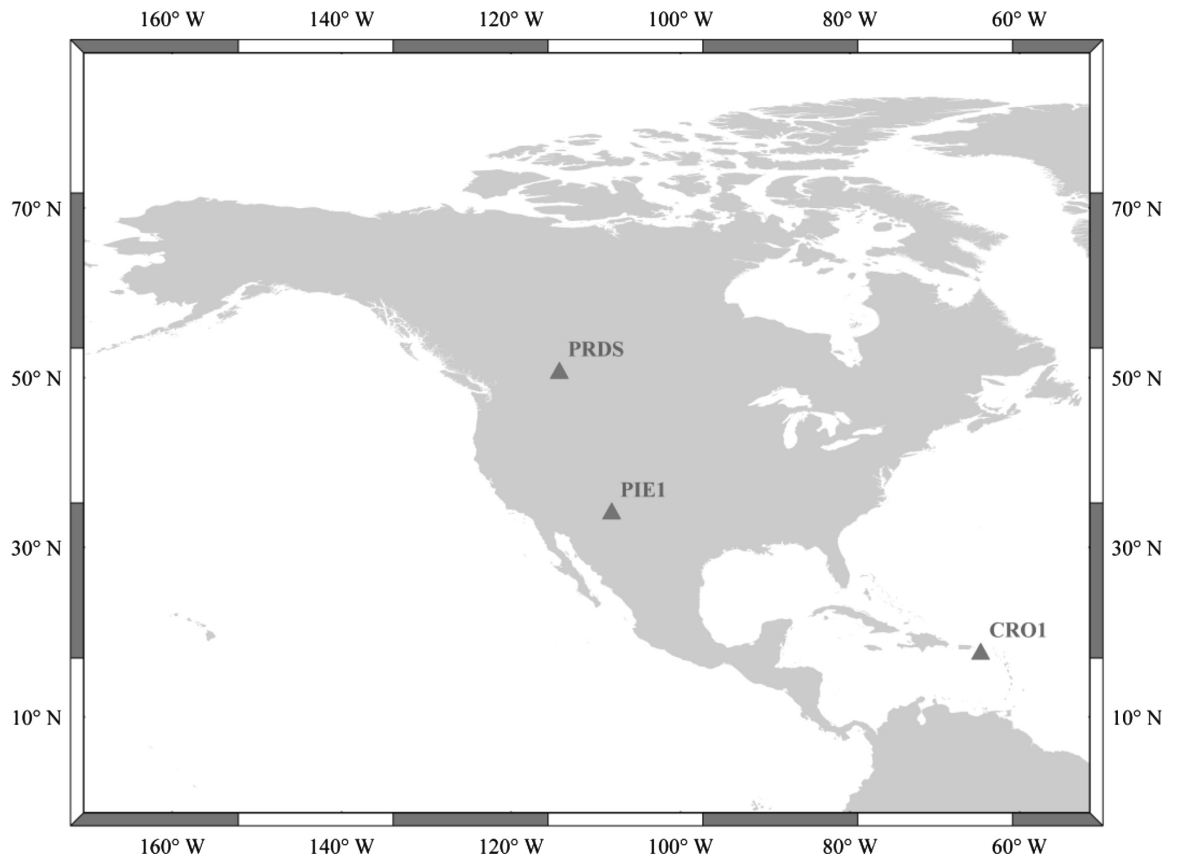

Fig. 3 IGS stations used in the analysis

Table 1 Characteristics of the examined stations

Table $2 \quad \mathrm{~F}_{10.7}$ and $\mathrm{A}_{\mathrm{P}}$ indices for the examined days (OMNIWeb 2015)

\begin{tabular}{llll}
\hline Station & Latitude & Longitude & Receiver type \\
\hline CRO1 & $17.7569^{\circ}$ & $295.4157^{\circ}$ & ASHTECH UZ-12 \\
PIE1 & $34.3015^{\circ}$ & $251.8811^{\circ}$ & JAVAD TRE_G3TH DELTA \\
PRDS & $50.8713^{\circ}$ & $245.7065^{\circ}$ & TPS NET-G3A \\
\hline
\end{tabular}

\begin{tabular}{lll}
\hline DOY & $\begin{array}{l}\text { Solar } \\
\text { flux-F } 10.7 \mathrm{~cm}\end{array}$ & $\begin{array}{l}\text { Geomagnetic } \\
\text { index }-\mathrm{A}_{\mathrm{P}}\end{array}$ \\
\hline 360 & 120.6 & 2 \\
361 & 126.3 & 1 \\
362 & 130.1 & 2 \\
\hline
\end{tabular}

file (IGS 2015). Figure 4 shows the flow chart of the proposed steps for the phasesmoothed method and its estimation procedure.

For the levelled carrier phase method, the phase observations have been smoothed using Eq. 7 and thus the slant TEC values have been computed using Eq. 12. In order to validate the accuracy of the examined smoothing methods, the slant TEC values have been estimated and compared with the final IGS-GIM and NOAA US-TEC (NOAA 2015) counterparts. For the IGS-GIM model, the vertical TEC values have been extracted using Eq. 14. Then, the vertical TEC values have been converted into the slant TEC using the SLM mapping function (Eq. 13). The effective height has been selected to be $350 \mathrm{~km}$. For 
Fig. 4 Flow chart of phasesmoothed code method procedure

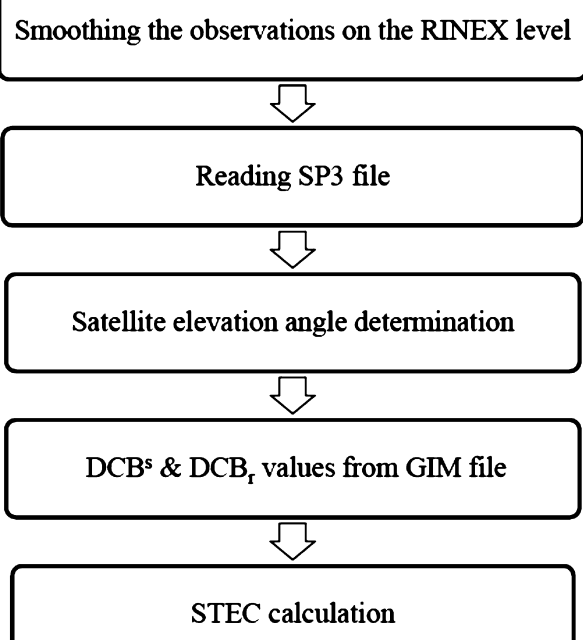

the NOAA maps, the slant TEC values have been interpolated using Eq. 14. In order to estimate the slant TEC values every $15 \mathrm{~min}$, the temporal interpolation method has been used as given in Eq. 15.

\section{Results and analysis}

For a single station, the slant TEC from a number of different satellites arcs are computed in order to study the effect of satellite DCB and elevation angle on the computed values. Therefore, the effect of the day time variability on the slant TEC values is assessed. In addition, the slant TEC between the same satellite and the three examined stations is determined in order to investigate the effect of receiver DCB and station latitude dependency.

Figure 5 shows the temporal variability of both the elevation angle and the slant TEC for satellite G07 arc, as an example, observed by the stations CRO1, PIE1 and PRDS for the three successive experimental days, respectively. It is shown that the estimated TEC from the phase-smoothed code observations is close to both IGS and NOAA, however, with a scattered shape. The scatter of the extracted STEC increases at station CRO1, locates at low latitude, and decreases gradually at station PRDS in the three examined days. The scatter size is based on the number of the processed observations in the smoothing interval. The arc time is about $4 \mathrm{~h}$ for station CRO1, while it is about $6 \mathrm{~h}$ for station PIE1 as well as station PRDS in the three examined days. Furthermore, the magnitude of the departure decreases as the elevation angle increase. Also, the phase-smoothed code introduces negative slant TEC values for station PRDS in the second day due to the data quality, satellite and receiver DCBs effects. For the levelled carrier phase, it provides smoothed shapes of slant TEC with an offset from both IGS and NOAA values. The offset value depends on the station location, where its magnitude varies from station CRO1 than station PRDS passing through station PIE1. 
CRO1, DOY 360

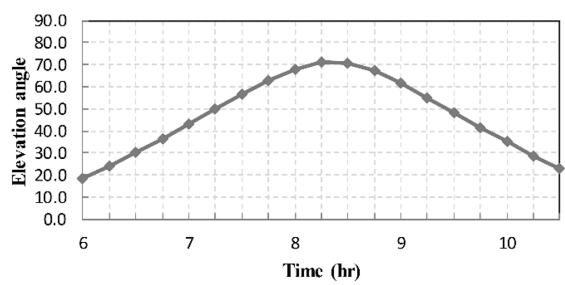

PIE1, DOY 360

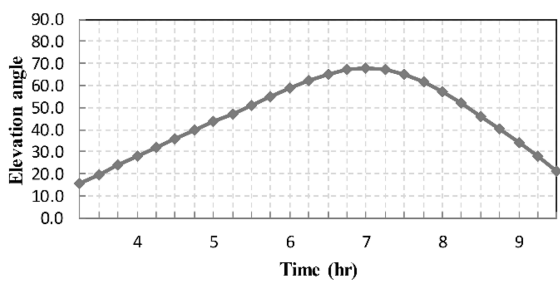

PRDS, DOY 360

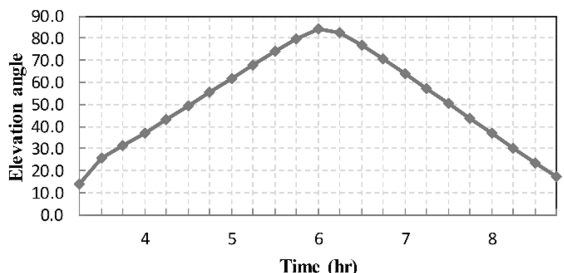

CRO1, DOY 361

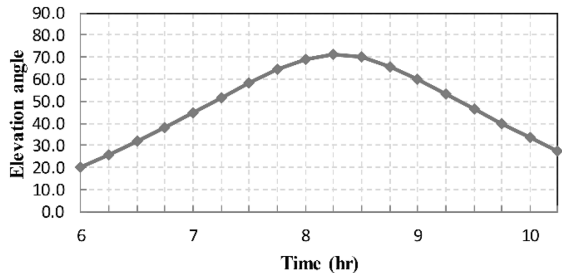

PIE1, DOY 361

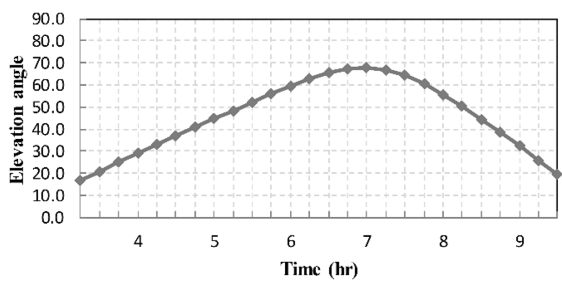

CRO1, DOY 360

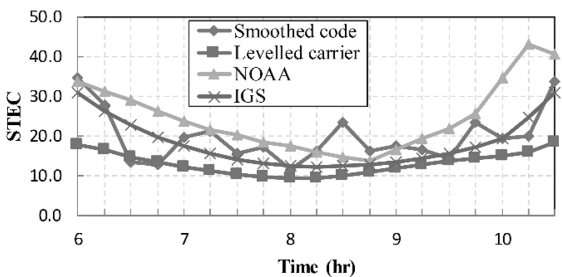

PIE1, DOY 360

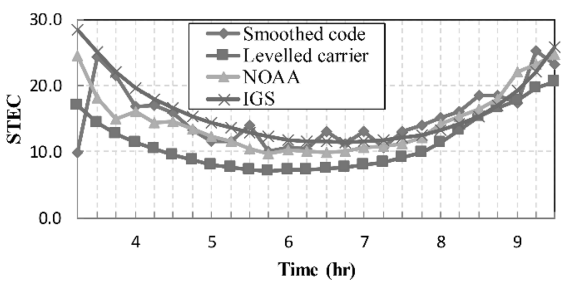

PRDS, DOY 360

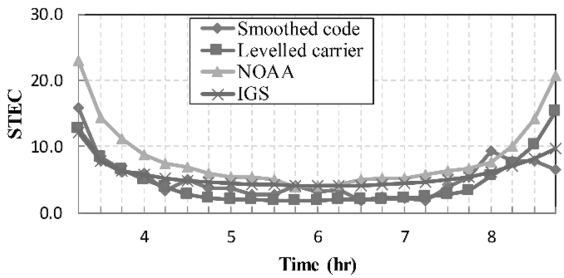

CRO1, DOY 361

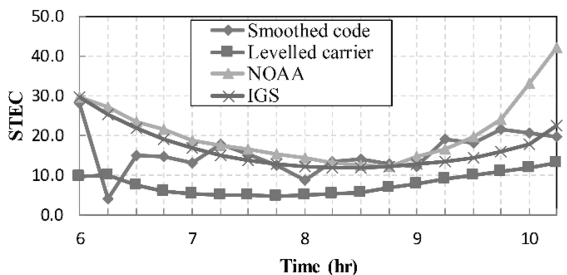

PIE1, DOY 361

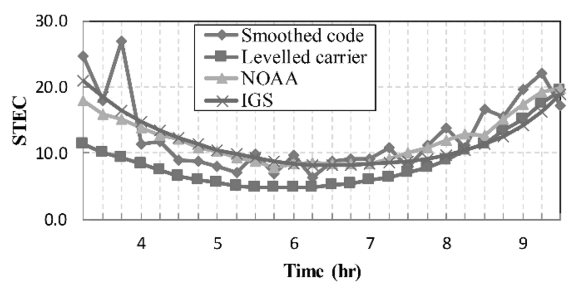

Fig. 5 Slant TEC between G07 and the three examined stations 

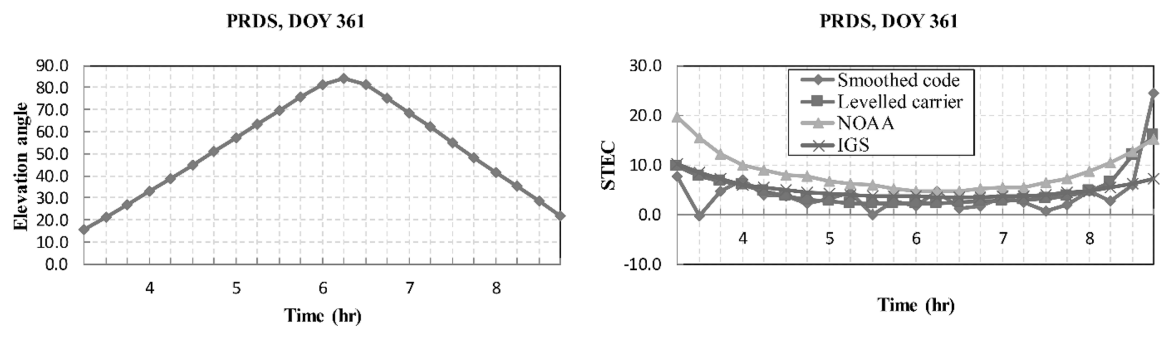

CRO1, DOY 362
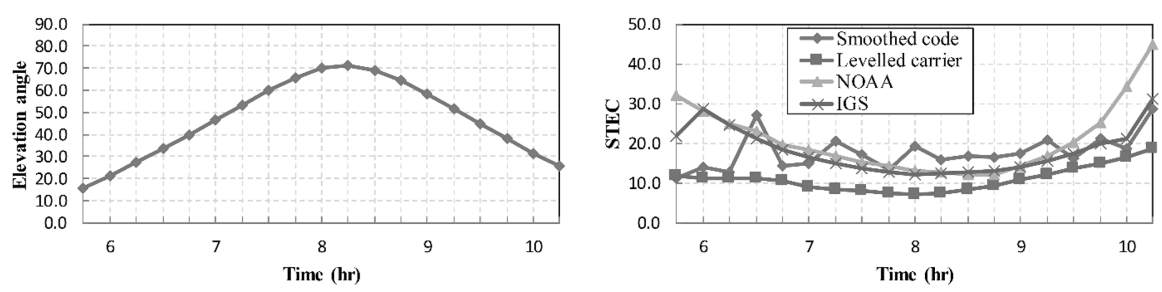

PIE1, DOY 362
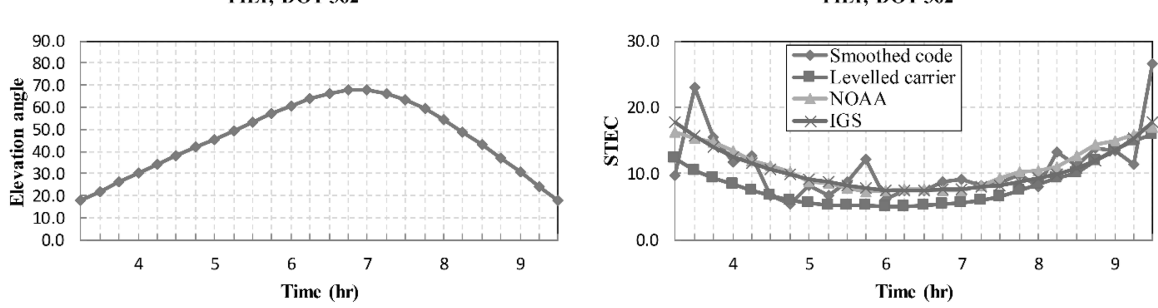

PRDS, DOY 362
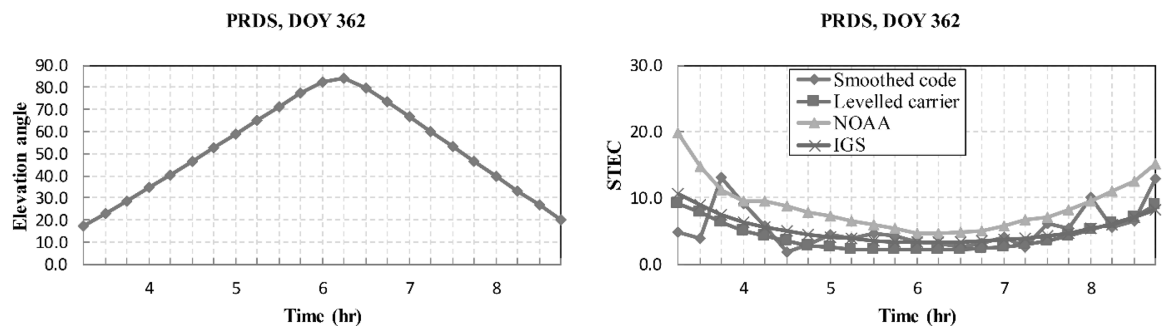

Fig. 5 continued

Table 3 summarizes the mean and the standard deviation (STD) of the differences between the estimated slant TEC and the IGS-GIM and NOAA, respectively. The results from three satellite arcs G07, G13 and G16 are given as examples. The results reveal that for the low latitude station CRO1 the computed TEC from the phase-smoothed code is more accurate than that obtained through the levelled carrier phase, where it is close to IGS-GIM as well as NOAA in the three examined days. For station PIE1, at mid-latitude region, the accuracy of the estimated slant TEC values from phase-smoothed code observations are better than the carrier phase levelling counterparts. For station PRDS, the phase-smoothed method is also more accurate than the levelled carrier phase method. However, the estimated standard deviation values from the levelled carrier phase method 
Table 3 Statistical analysis for the estimated STEC differences

\begin{tabular}{|c|c|c|c|c|c|c|c|c|c|c|}
\hline \multirow[t]{3}{*}{ Station } & \multirow[t]{3}{*}{ Sat. } & \multirow{3}{*}{$\begin{array}{l}\text { Arc time } \\
\text { (minutes) }\end{array}$} & \multicolumn{4}{|c|}{ IGS-GIM (TECU) } & \multicolumn{4}{|c|}{ NOAA (TECU) } \\
\hline & & & \multicolumn{2}{|c|}{ Smoothed code } & \multicolumn{2}{|c|}{$\begin{array}{l}\text { Levelled } \\
\text { carrier }\end{array}$} & \multicolumn{2}{|c|}{ Smoothed code } & \multicolumn{2}{|c|}{$\begin{array}{l}\text { Levelled } \\
\text { carrier }\end{array}$} \\
\hline & & & Mean & STD & Mean & STD & Mean & STD & Mean & STD \\
\hline \multicolumn{11}{|c|}{$\mathrm{DOY}=360$} \\
\hline \multirow[t]{3}{*}{ CRO1 } & G07 & $360-630$ & -1.530 & 4.717 & 5.125 & 3.629 & 4.902 & 7.513 & 11.557 & 6.321 \\
\hline & G13 & $285-465$ & -2.266 & 9.556 & 5.063 & 4.938 & 2.738 & 9.965 & 10.067 & 5.177 \\
\hline & G16 & $75-465$ & 3.789 & 7.197 & 3.473 & 4.397 & 8.450 & 6.406 & 8.135 & 2.677 \\
\hline \multirow[t]{3}{*}{ PIE1 } & G07 & $195-570$ & 0.901 & 4.018 & 4.844 & 3.010 & -0.648 & 3.812 & 3.294 & 1.373 \\
\hline & G13 & $150-480$ & 0.966 & 7.124 & 6.032 & 4.421 & -1.679 & 8.139 & 3.386 & 3.342 \\
\hline & G16 & $60-360$ & 1.983 & 7.002 & 5.837 & 4.231 & 1.150 & 4.429 & 5.005 & 1.518 \\
\hline \multirow[t]{3}{*}{ PRDS } & G07 & $195-525$ & 0.605 & 1.658 & 1.060 & 1.928 & 3.275 & 3.155 & 3.729 & 1.694 \\
\hline & G13 & $135-435$ & 0.532 & 5.564 & 0.564 & 2.960 & 3.252 & 6.430 & 3.284 & 2.577 \\
\hline & G16 & $105-375$ & 1.707 & 2.998 & 1.364 & 2.434 & 4.562 & 2.555 & 4.219 & 1.004 \\
\hline \multicolumn{11}{|c|}{$\mathrm{DOY}=361$} \\
\hline \multirow[t]{3}{*}{ CRO1 } & G07 & $360-615$ & 1.063 & 6.120 & 8.910 & 4.402 & 5.070 & 7.456 & 12.917 & 6.122 \\
\hline & G13 & $270-465$ & 5.419 & 12.980 & 12.840 & 5.062 & 4.778 & 13.025 & 12.199 & 5.499 \\
\hline & G16 & $105-480$ & 5.381 & 9.184 & 6.938 & 5.649 & 5.334 & 8.705 & 6.890 & 4.693 \\
\hline \multirow[t]{3}{*}{ PIE1 } & G07 & $195-570$ & -0.907 & 3.384 & 3.230 & 2.979 & -0.575 & 3.295 & 3.562 & 1.567 \\
\hline & G13 & $150-465$ & 1.154 & 5.881 & 4.654 & 3.806 & 0.799 & 5.184 & 4.299 & 3.078 \\
\hline & G16 & $60-330$ & 3.207 & 7.657 & 5.169 & 3.350 & 5.180 & 5.963 & 7.143 & 1.744 \\
\hline \multirow[t]{3}{*}{ PRDS } & G07 & $195-525$ & 0.928 & 4.424 & 0.186 & 2.434 & 4.427 & 4.524 & 3.685 & 2.119 \\
\hline & G13 & $120-420$ & 0.780 & 3.122 & 0.786 & 1.665 & 4.742 & 5.054 & 4.748 & 3.486 \\
\hline & G16 & $105-375$ & 1.761 & 3.321 & 1.363 & 3.642 & 6.329 & 5.220 & 5.930 & 2.388 \\
\hline \multicolumn{11}{|c|}{$\mathrm{DOY}=362$} \\
\hline \multirow[t]{3}{*}{ CRO1 } & G07 & $345-615$ & 0.283 & 6.229 & 7.067 & 3.899 & 3.254 & 8.494 & 10.038 & 6.294 \\
\hline & G13 & $270-465$ & 4.902 & 7.467 & 7.952 & 5.338 & 4.778 & 7.465 & 7.827 & 5.008 \\
\hline & G16 & $60-480$ & 2.906 & 7.774 & 6.651 & 1.847 & 6.324 & 7.664 & 10.069 & 2.579 \\
\hline \multirow[t]{3}{*}{ PIE1 } & G07 & $195-570$ & -0.268 & 3.438 & 2.484 & 1.580 & 0.138 & 3.538 & 2.891 & 1.250 \\
\hline & G13 & $120-465$ & 2.905 & 6.436 & 3.469 & 2.655 & 2.806 & 6.020 & 3.370 & 2.439 \\
\hline & G16 & $75-345$ & 1.613 & 3.336 & 3.413 & 2.580 & 2.708 & 2.016 & 4.508 & 1.406 \\
\hline \multirow[t]{3}{*}{ PRDS } & G07 & $195-525$ & -0.192 & 2.743 & 0.940 & 0.635 & 3.350 & 3.704 & 4.482 & 1.777 \\
\hline & G13 & $105-435$ & 2.850 & 4.985 & 0.969 & 1.043 & 7.443 & 8.085 & 5.561 & 5.212 \\
\hline & G16 & $105-375$ & 2.809 & 3.125 & 2.144 & 1.276 & 6.580 & 4.520 & 5.915 & 3.103 \\
\hline
\end{tabular}

are smaller than the phase-smoothed code counterparts. This means that the levelled carrier phase ionospheric observable provides a shift by a semi-constant value, while the phasesmoothed code ionospheric observable is scattered over the same station. 


\section{Conclusion}

GPS has become a powerful tool for real-time ionospheric monitoring and space weather studies. Different data smoothing techniques have been proposed in order to increase the accuracy of the estimated TEC by using both carrier phase and code observations. This paper aims to investigate the accuracy and performance of two smoothing techniques; phase-smoothed code and levelled carrier phase techniques. GPS data from three IGS reference stations in North America CRO1, PIE1 and PRDS in three successive days (DOY 360, 361 and 362 in 2013) have been downloaded. The stations distribution represents different latitudes low, medium and high, respectively. The accuracy of the slant TEC values from the examined methods have been estimated and compared with the IGS-GIM and NOAA US-TEC counterparts.

The results show that the computed TEC from the phase-smoothed code technique is close to the IGS-GIM as well as NOAA but with a scattered behaviour. The scatter size depends upon the station location, the quality of code data and number of observations used in the smoothing procedure. In addition to, the satellite and receiver DCBs influence on the estimated TEC and in some cases negative TEC values can be introduced. For the levelled carrier phase method, it represents the precise measure of relative TEC with a semi-constant, latitude dependent, shift from both IGS-GIM and NOAA. Furthermore, the extracted ionospheric observables are influenced by systematic levelling error due to code noise and multipath effects. Also, the satellite and receiver DCBs are translated to the extracted TEC in the levelling procedure. It can be concluded that the absolute accuracy of phase-smoothed code technique is better but the levelled carrier phase technique still provides relative and calibrated TEC measurements.

Also, the intraday variation of the arc time for the same satellite over the same station and the daytime variation of the receiver differential code bias may affect on the estimated total electron content values.

Acknowledgments The authors would like to thank L. Ciraolo, ICTP- Italy, for providing his software for TEC determination using levelled carrier phase.

\section{References}

Araujo-Pradere EA, Fuller-Rowell TJ, Spencer PSJ et al (2007) Differential validation of the US-TEC model. Radio Sci 42:RS3016. doi:10.1029/2006RS003459

Arikan F, Nayir H, Sezen U, Arikan O (2008) Estimation of single station inter frequency receiver bias using GPS-TEC. Radio Sci 43:RS4004. doi:10.1029/2007RS003785

Ciraolo L, Azpilicueta F, Brunini C, Meza A, Radicella SM (2007) Calibration errors on experimental slant total electron content (TEC) determined with GPS. J. Geod 81(2):111-120

Dach R, Hugentobler U, Fridez P, Meindl M (2007) Bernese GPSSoftware version 5.0. Astronomical Institute, University of Berne (AIUB)

Hernández-Pajareset M, Juan JM, Sanz J et al (2009) The IGS VTEC maps: a reliable source of ionosphericinformation since 1998. J Geod 83(3):263-275

IGS (2015) International GNSS service. ftp://cddis.gsfc.nasa.gov/. Accessed May 15, 2015

Kleusberg A, Teunissen PJG (1998) GPS for geodesy. Springer, Berlin

Liu Z, Gao Y, Skone S (2005) A study of smoothed TEC precision inferred from GPS measurements. Earth Planets Space 57(11):999-1007

Mannucci AJ, Wilson BD, Yuan DN et al (1998) A global mapping technique for GPS-derived ionospheric total electron content measurements. Radio Sci 33(3):565-582

NOAA (2015) National Oceanic and Atmospheric Administration. https://www.ngdc.noaa.gov/stp/IONO/ USTEC/. Accessed on May 15, 2015 
OMNIWeb (2015) http://omniweb.gsfc.nasa.gov/form/dx1.html. Accessed September 25, 2015

Otsuka Y, Ogawa T, Saito A et al (2000) A new technique for mapping of total electroncontent using GPS network in Japan. Earth Planets Space 54(1):1-23

Schaer S (1999) Mapping and predicting the earth's ionosphere using the global positioning system. Ph.D. thesis, University of Bern, Switzerland

Schaer S, Gurtner W, Feltens J (1998) IONEX: the IONosphere mapexchange format version 1. In: Proceedings of the IGS AC Workshop, pp 233-247

Springer TA (2000) Modeling and validating orbits and clocks using the global positioning system. Ph.D. thesis, University of Bern, Switzerland 